\title{
TEMA CONTEXTUAL COMO POSSIBILIDADE TRANSDISCIPLINAR NA EDUCAÇÃO INTERCULTURAL
}

\section{CONTEXTUAL THEMES AS A TRANSDISCIPLINARY POSSIBILITY IN INTERCULTURAL EDUCATION}

Luciana De Oliveira Dias ${ }^{14}$

\begin{abstract}
This text is the result of an intellectual effort to better understand contextual themes as alternatives to disciplinary limitations, inherited from modern science and rationalism that were consolidated in the seventeenth century, in environments of knowledge production. Reflections provoked in some classes that were developed in the undergraduate course in Indigenous Intercultural Education, of the Federal University of Goiás, enabled a more robust discussion about multi/inter/trans-disciplinarity as a possibility for access, combination, enlargement and generation of intercultural knowledge. Contextual themes have shown that an expansion of epistemic horizons occurs in the moments of establishment of pedagogical practices and dialogical and reflective environments composed of agents that start from different cultural bases.
\end{abstract}

\section{RESUMO}

O presente texto é resultado de um esforço intelectual para uma melhor compreensão dos temas contextuais como alternativas às limitações disciplinares, herdadas da ciência moderna e do racionalismo que se consolidaram no século XVII, em ambientes de produção do conhecimento. Reflexões provocadas em algumas aulas que foram desenvolvidas no curso de graduação em Educação Intercultural Indígena, da Universidade Federal de Goiás, habilitaram uma discussão mais robusta acerca da multi/inter/trans-disciplinaridade como possibilidade para o acesso, combinação, alargamento e geração de saberes interculturais. Os temas contextuais têm demonstrado que uma ampliação de horizontes epistêmicos acontece nos instantes de instauração de práticas pedagógicas e ambientes dialógicos e reflexivos compostos por agentes que partem de bases culturais diferenciadas.

\section{KEYWORDS}

Contextual theme; Transdisciplinarity; Plural Knowledge

\section{PALAVRAS-CHAVE}

Tema Contextual; Transdisciplinaridade; Saberes Plurais

\section{Introdução}

O que segue apresentado neste texto é resultado de um esforço intelectual cujo objetivo mais geral foi realizar uma discussão com ênfase nos temas contextuais, relacionando-os com transdisciplinaridade. Essa busca por clareza conceitual permite afirmar que os temas contextuais são eixos orientadores de práticas pedagógicas que são inseridos

\footnotetext{
${ }^{14}$ Doutora em Ciências Sociais, Universidade Federal de Goiás: professoralucianadias@gmail.com
} 
nos currículos como propostas político-pedagógicas com potencialidade para alargar conhecimentos, já que não operam a partir daquilo que é previamente estabelecido como disciplina, mas, sobremaneira, a partir de uma espécie de fusão de horizontes (CARDOSO DE OLIVEIRA, 1995) epistêmicos.

Para imprimir neste manuscrito argumentos elucidativos do que sejam e como se realizam os temas contextuais, foi desenvolvido um estudo de algumas aulas acontecidas no curso de formação superior de docentes indígenas, Educação Intercultural, da Universidade Federal de Goiás - UFG. A Educação Intercultural funciona, desde o ano de 2007, no Núcleo Takinahakỹ de Formação Superior Indígena da UFG e conta hoje com mais de vinte povos compondo seu corpo discente, quais sejam: Apinajé, Bororo, Canela, Gavião, Guajajara, Javaé, Juruna, Kaiapó, Kamaiurá, Karajá, Krahô, Krikati, Kuikuro, Tapirapé, Tapuia, Timbira, Xakriabá, Xambioá, Xavante, Xerente, Yawalapiti e Waurá, perfazendo um total de 281 estudantes neste ano de 2017. Esses estudantes, que são também docentes em suas aldeias, são atendidos por doze professores e professoras do quadro permanente (dentre os quais eu me incluo) e alguns/algumas colaboradores/as.

As aulas são desenvolvidas em turmas que são constituídas por estudantes pertencentes a diferentes povos indígenas, o que favorece complexos encontros interculturais. As aulas que foram selecionadas para subsidiarem a produção das reflexões e discussões aqui apresentadas aconteceram no ano de 2016 durante os temas contextuais nos quais atuo como docente, quais sejam: "Direitos Indígenas" e "Direitos sobre Conhecimentos Tradicionais". Esses temas contextuais são oferecidos para estudantes que se encontram na metade do curso e suas ementas recebem um enfoque na relação entre sistemas jurídicos próprios das sociedades indígenas e suas relações com os direitos institucionalizados pelo Estado. São tematizadas questões de identidade, direitos indígenas, luta e resistência. A proposta, ao enfocar nesses dois temas contextuais, foi acentuar algumas discussões sobre questões de dignidade, cidadania e realização de justiças.

Um aprendizado a ser socializado é o de que os temas contextuais habilitam uma discussão robusta acerca da multi/inter/trans-disciplinaridade como possibilidade para o acesso, combinação, alargamento e geração de saberes interculturais. Neste sentido, e a partir da minha experiência no âmbito da Educação Intercultural, considero que os temas 
contextuais têm demonstrado que uma ampliação de horizontes epistêmicos acontece nos instantes de instauração de ambientes (a) interculturais, já que compostos por agentes que partem de bases culturais diferenciadas; (b) dialógicos, já que o pressuposto é a escuta e enunciação plurais e horizontalizadas; e, (c) reflexivos, já que se evidencia o esforço por avançar, maturar, expandir e problematizar representações, significações, sentimentos e ideias.

\section{Uma interculturalidade possível: Educação Intercultural Indígena na UFG}

A importância desta investida de textualização de uma interculturalidade possível sustenta-se na emergente necessidade de evidenciar, contemporaneamente, ações que sejam reveladoras de saberes, adjetivados aqui de interculturais. Destaque-se que a interculturalidade sustenta-se em uma horizontalidade epistêmica, ou seja, saberes que partem de pontos diferenciados devem ser tomados de forma não hierarquizada, na qual um não se sobreponha a outro. Os contextos de interculturalidade têm o potencial de provocar abalos em estruturas socioculturais responsáveis pela cristalização de perversas hegemonias. A interculturalidade, como uma ação contínua, e até insurgente com seu potencial decolonial (WALSH, 2015), ajuda a pensar e intervir em processos desumanizantes de seres humanos (FREIRE, 2013).

A Educação Intercultural da UFG, que recebeu seus primeiros estudantes em 2007, visa habilitar docentes indígenas a lecionarem em escolas indígenas de ensino fundamental e médio, nas quais já atuam. O curso é resultado de um empenho no atendimento a uma demanda das comunidades indígenas no que se refere à formação superior de docentes indígenas. A proposta curricular do curso conta com ações presenciais na UFG - quando os/as estudantes se deslocam para a universidade - e, nas aldeias - quando os/as docentes se deslocam para as aldeias e realizam atividades de orientação, acompanhamento e integração com a comunidade. A Educação Intercultural apresenta uma estrutura composta por dois anos iniciais de Matriz Básica e três anos finais de Matriz de Formação Específica, na qual os/as estudantes escolhem aproximar seus estudos de três áreas específicas, quais sejam: Ciências da Cultura, Ciências da Linguagem ou Ciências da Natureza.

O curso de Educação Intercultural, que pode ser integralizado com cinco anos de estudos, é destinado a povos indígenas que, conforme previsto no Projeto Pedagógico do 
Curso (PPC), demandam por definição de ações de defesa de seus direitos, por adoção de políticas de manutenção de suas línguas e culturas maternas e de suas terras, e, por um delineamento de políticas de desenvolvimento sustentável. A pluralidade cultural e o respeito à diferença têm guiado as ações no âmbito da Educação Intercultural, que apresenta como eixos epistemológicos: a interculturalidade, a diversidade, a sustentabilidade e a transdisciplinaridade. No contexto da Educação Intercultural, o esforço tem sido de concretizar uma política epistêmica da interculturalidade (WALSH, 2009) na qual o campo educativo colabora para fazer erodir estruturas epistêmicas de colonialidade.

A interculturalidade possível emerge contemporaneamente, sobremaneira em ambientes de ensino e aprendizagem, como ações desestabilizadoras de padrões de colonialidade que foram fortemente ancorados em processos de inferiorização, ou como chamado anteriormente, de desumanização, de determinados segmentos humanos. Aníbal Quijano (2005, p.107), ao discutir sobre a instituição do padrão de poder mundial que teve como base o capitalismo colonial/moderno e eurocentrado, é assertivo ao afirmar que "um dos eixos fundamentais desse padrão de poder é a classificação social da população mundial de acordo com a ideia de raça". O mesmo autor segue complementando que raça é um construto que exprime a experiência de dominação colonial. A interculturalidade, ao concretizar-se, evidencia esse padrão de poder e o problematiza, denunciando seu caráter colonial.

A educação escolar é herdeira e, não raras vezes, reprodutora eficaz de dinâmicas que emolduram saberes em disciplinas, convertendo-as em instrumentos inibidores de uma pluralidade e diversidade de saberes. Embora seja fundamental reconhecer que um hegemônico padrão de poder mundial tem se mantido estável, sendo que adentrou nas mais diversas instituições, reproduzindo estruturas hierarquizadas e de opressão, contemporaneamente é possível notar nichos, em processos de expansão e fortalecimento, nos quais a interculturalidade tem permitido a livre manifestação e vibrante integração de múltiplos saberes.

No âmbito da Educação Intercultural da UFG os encontros que tem acontecido em contextos da universidade e da aldeia têm permitido complexas e dinâmicas tessituras de, e entre saberes. No decorrer das aulas de "Direitos Indígenas" e "Direitos sobre 
Conhecimentos Tradicionais", os/as estudantes, representantes de seus povos, portanto coletividades, afirmam de maneira enfática seu direito de seguirem transmitindo para as novas gerações hábitos, costumes, valores, saberes e tradições que têm garantido sua própria existência enquanto povo. Ao mesmo tempo, esses estudantes apresentam uma postura altamente receptiva, até por entender que esse também é um direito, a um conhecimento assentado e cristalizado nas universidades, muitas vezes tomado como universal e que pode ser chamado de "conhecimento ocidental" (NASCIMENTO, 2014).

Em atendimento a uma proposta de atividade escrita em sala de aula, cuja temática eram os direitos sobre os conhecimentos tradicionais, um grupo de cinco estudantes Xavante descreve o wedenhóró e as wapté nhiptsi (pulseiras e tornozeleiras feitas de fibras vegetais que são torcidas, enroladas e amarradas nos pulsos, tornozelos e no cabelo na parte da nuca em instantes ritualizados) da seguinte maneira:

wedenhóró é um saber tradicional antigo e que está vivo, ainda é trabalhado e praticado. São os homens que procuram pegar no mato para a produção. Ele é produzido em vários tipos e tamanhos para a realização das festas. Wapté nhiptsi são as cordinhas de tamanho enorme, que é somente uma corda, usada especificamente por adolescentes. Com essa corda os wapté ${ }^{15}$ aprendem através de ensinamentos dos anciãos. Assim os conhecimentos vêm passando de geração para geração. Portanto, ainda hoje seguimos os conhecimentos de nossos antepassados. Isso para não perdermos nossa lei tradicional existente. É o que temos.

Estão contidas no excerto destacado no parágrafo anterior, algumas compreensões que revelam, com base na descrição do wedenhóró xavante, sistemas jurídicos complexos, particulares, eficazes, valorizados e reconhecidos pelo próprio grupo, ainda que mantenha pouca, ou nenhuma relação com um sistema jurídico nacional único. Uma profunda interculturalidade está posta em cena e deve ser considerada para a ativação de instantes dialógicos reveladores da pluralidade e diversidade de saberes, alargadores de concepções reduzidas pelas disciplinas, como o direito por exemplo. Durante as aulas, as compreensões expressas abriram potentes canais de comunicação horizontalizada entre questões de direito e questões de ordenamentos societários, lei e moral, culturas indígenas, saberes xavante etc.

\footnotetext{
${ }^{15}$ Assim são chamados os adolescentes quando estão na casa dos solteiros realizando o ritual de passagem à vida adulta.
} 
Neste sentido, aspectos relacionados à lei e moral (para não perdermos nossa lei tradicional existente), saberes e conhecimentos tradicionais (seguimos os conhecimentos de nossos antepassados), ordenamentos societários (os wapté aprendem através de ensinamentos dos anciãos) e reprodução da vida (É o que temos - que pode ser interpretado como: É o que somos) são relatados de maneira conjugada, integrada, entrelaçada e indissociável, ou seja: sem fragmentação ou cisão, mas, da forma como são vivenciados. É assim que eles começam falando do que de maneira reduzida alguns chamariam de "artesanato" - sobretudo a partir da Antropologia, ou das Artes, e que são as pulseiras e tornozeleiras - e avançam, durante a narrativa, em um contínuo, definindo o wedenhóró como uma ontologia xavante.

$\mathrm{Na}$ busca por uma melhor compreensão do wedenhóró, como um ritual de passagem à vida adulta que é garantido, e desejado, a todos os adolescentes xavante, poderse-ia considerar que um direito de toda criança xavante é ser um wapté para aprender a ser um xavante adulto e compartilhar ensinamentos. Com a realização desse ritual xavante, que fora rapidamente descrita acima, é a própria justiça que se realiza e se realiza não somente para um indivíduo, mas para toda uma comunidade. O que aparece como evidente é o fato de que há uma pluralidade de concepções de justiça, relativa aos diversos povos, que experimenta tensões e incompatibilidades, em variados instantes, quando há uma aproximação com uma concepção de sistema jurídico único, o que, por sua vez, evidencia também as limitações de campos do conhecimento científico, ou disciplinas, em contextos de interculturalidade.

Gersem José dos Santos Luciano (2006, p.87), ao discutir sobre a relação entre cidadania e autonomia indígena, em contextos de diversidade cultural, propõe a superação de uma noção ainda limitada e eurocêntrica de cidadania. Esta noção que ainda é vastamente entendida como direitos e deveres comuns aos indivíduos que partilham os mesmos símbolos e valores de uma nação deve adentrar em possibilidades compreensivas que considerem legítimo o reconhecimento à diferença e que assegurem a igualdade de condições. Para o antropólogo baniwa supracitado, "somente o diálogo intercultural efetivo é capaz de possibilitar a coexistência das lógicas da etnia e da cidadania em um mesmo espaço social e territorial." (LUCIANO, 2006, p.89). Com base nesta consideração, o autor explora um 
terreno discursivo capaz de elucidar uma compreensão mais refinada de cidadania diferenciada, interculturalidade e descolonização de saberes.

A partir desta perspectiva, a interculturalidade sinaliza para a efetivação do usufruto de direitos universais por sujeitos, que são também cidadãos, sem que se percam direitos específicos relativos às culturas, às tradições, aos valores e aos saberes. Esta trajetória é possível de ser trilhada por intermédio da concretização de uma "cidadania diferenciada" que se solidifica sobre as bases de uma "educação de qualidade e adequada" (LUCIANO, 2006, p.92) às realidades locais, ou uma educação intercultural. Essa educação, ao assegurar processos autônomos de vida e vincular-se a princípios de direitos humanos, descortina um significativo potencial para a promoção de uma emancipação sociocultural, política, jurídica, econômica e epistêmica. Neste ínterim, a autonomia emerge como uma forma de exercício à livre autodeterminação, à produção de conhecimentos e ao reconhecimento, e à valorização de saberes interculturais.

$\mathrm{Na}$ Educação Intercultural da UFG a interculturalidade tem se tornado uma possibilidade concreta e um exercício constante de prática pedagógica, sobretudo por meio desenvolvimento dos temas contextuais que vinculam educação, autonomia, pluralismo e diversidade, dialogicidade e protagonismo no campo dos saberes. Práticas pedagógicas empreendidas por estudantes da Educação Intercultural e por docentes da UFG que atuam nesse mesmo curso têm sido consolidadas sobre bases epistêmicas interculturais que pressupõem uma articulação e integração entre múltiplos e complexos saberes. Esse fazer pedagógico pode ser lido como decolonial por denunciar as bases colonizadoras que sustentam os conhecimentos ocidentais e por revelar a multiplicidade e diversidade de saberes indígenas que se sustentam sobre outras lógicas e outras cosmologias.

\section{Temas Contextuais e questões de multi/inter/trans-disciplinaridade}

Os temas contextuais são construções pedagógicas que, no âmbito da Educação Intercultural da UFG, têm potencializado movimentações epistêmicas que colocam em profundo diálogo um conjunto de saberes emoldurados em um conhecimento ocidental e disciplinar e um outro conjunto de saberes indígenas que foram historicamente desprezados em processos de produção e avanço do conhecimento no interior das universidades. A este segundo conjunto de saberes há que se reconhecer seu potencial para a realização, a partir do 
contato e das trocas que acontecem em contextos pedagógicos, daquilo que Walter D. Mignolo (2010) chamou de "giro epistêmico" como condição essencial para a emergência de um "pensamento decolonial".

Neste ponto deste texto, o esforço mais marcado é por refinar a concepção de tema contextual. A partir daí e em concordância com Maria do Socorro Pimentel da Silva (2017, p.207), destaco que os temas contextuais favorecem uma espécie de "retomada de saberes apagados, escondidos em muitas memórias de sábios, perdidos entre gerações.". A realização de um tema contextual promove uma dinamização de conhecimentos e saberes, sem que sejam ativados processos de hierarquização. $O$ tema contextual promove também uma espécie de politização do fazer pedagógico e da movimentação de saberes, já que denuncia uma colonialidade do saber ao mesmo tempo em que reivindica saberes decoloniais, estes que devem considerar de maneira horizontalizada toda a multiplicidade e diversidade de saberes.

O desenvolvimento dos temas contextuais tem conduzido ao acesso, combinação, alargamento e geração de saberes interculturais, colocando em primeiro plano seu caráter e potência decolonial. Além da interculturalidade - que conforme realça Catherine Walsh (2007) é gestada muito mais em um movimento "étnico-social" e menos em uma "instituição acadêmica", daí a interculturalidade não estar sustentada sobre os legados coloniais e eurocêntricos de uma ciência moderna -, a transdisciplinaridade é também um dos princípios do curso de Educação Intercultural da UFG. A transdisciplinaridade tem guiado uma interação entre os múltiplos saberes indígenas e as distintas áreas do conhecimento científico.

Em uma busca por maior clareza conceitual de transdisciplinaridade, segue uma rápida contextualização da disciplina no campo do conhecimento científico. Destaque-se que este é um empreendimento relevante porque permite adentrar em uma discussão que é inaugurada a partir da consideração do próprio sufixo da palavra trans-disciplinar. Durante o século XVII houve a consolidação da ciência moderna e do racionalismo, sobremaneira com base na afirmação da máxima de René Descartes (1596-1650) "Penso, logo existo". Foi assentada naquele período a perspectiva metódica cuja finalidade era dividir o objeto de estudo para estudar os seus elementos constituintes e, em momento subsecutivo, recompor o todo. A disciplina emergiu naquele momento histórico como um ramo do conhecimento 
científico. Assim sendo, compreende-se contemporaneamente como disciplinas, áreas do conhecimento científico tais quais a Matemática, Biologia, Psicologia, Sociologia etc.

A consolidação das disciplinas científicas levou à disciplinarização dos conhecimentos e a uma busca por especialização cada vez mais canalizada. O progresso experimentado pelo conhecimento científico foi condicionado pela especialização que ocupou o cenário como uma expressão das exigências analíticas. Todavia há que se destacar os altíssimos custos de uma especialização extremada tal qual a que pode ser observada hoje nas universidades. Olga Pombo (2003) pontua que a especialização extrema levou: (a) a uma forte institucionalização do trabalho científico; (b) a um distanciamento da vocação democrática da ciência; (c) a um fomento à competitividade e rivalidade entre comunidades científicas; (d) a uma fragilização na comunicação universal dos resultados. É possível estender essa discussão no direcionamento de que a especialização estremada fez com que a ciência ficasse presa a instituições que, por sua vez, aprisionam teorias e métodos em suas disciplinas. Todavia, esta será uma outra escolha temática, em outro texto.

No que se refere aos caminhos percorridos por esse processo de disciplinarização, a fragmentação, a partir dos anos 1970, tendeu a aumentar nas instituições produtoras de conhecimento. Paradoxalmente, a partir daquele mesmo período, a interdisciplinaridade começou a se fazer presente nas atividades e práticas no âmbito da produção do conhecimento. $\mathrm{O}$ efeito daquele movimento foi uma espécie de reordenamento disciplinar, caracterizado pelo surgimento de ciências de fronteira, como a Bioquímica, Geofísica, Sociobiologia, dentre outras e também pela emergência das interdisciplinas, tais quais a Psicologia industrial, a Sociologia das organizações etc.

Toda essa agitação nos cenários de produção do conhecimento científico, que é herdeiro da disciplinaridade consolidada com a ciência moderna e o racionalismo, fez com que aparecesse como protagonistas concomitantes a multidisciplinaridade, a interdisciplinaridade e a transdisciplinaridade. A dinâmica com que essa movimentação aconteceu, retirou qualquer estabilidade necessária às propostas que, não raras vezes, são apresentadas como superadas uma pela outra. Em decorrência dessa instabilidade conceitual, as três categorias, que são relativamente jovens em termos históricos nos limites do conhecimento científico, experimentam também um desgaste conceitual. Esse 
envelhecimento precoce, em termos práticos, tem indicado um retorno à disciplina que é ocupada pela pessoa que desenvolve a pesquisa como um setor de segurança e conforto. Ciente desse processo, apresento a seguir um esforço em compreender, explicar e evidenciar possibilidades concretas de exercício, de maneira combinada e não excludente, da multidisciplinaridade, da interdisciplinaridade e da transdisciplinaridade.

Uma abordagem multidisciplinar demonstra com exatidão a multiplicidade de áreas que compõem um conjunto mais amplo de conhecimentos institucionalizados. Pressupõe uma coordenação de áreas que operam a partir da especialização e que desnudam a pluralidade e a diferença. No que se refere à pluralidade, o avanço é significativo porque já que salta aos olhos uma realidade de produção do conhecimento composta por múltiplas possibilidades de aproximação de um mesmo objeto de pesquisa, daí o fato de algumas pessoas chamarem a abordagem multidisciplinar também de pluridisciplinar. Quanto à diferença, que também é revelada pela perspectiva multidisciplinar, o que pode ser notado é uma espécie de conversão da mesma em desigualdade, em decorrência do paralelismo entre áreas desde a multidisciplinaridade. Realço que a desigualdade nada mais é que a diferença reconhecida e hierarquizada (DIAS, 2012) em uma escala inventada que torna superior o lugar no qual se encontra o hegemônico, e inferior o lugar do subalternizado.

Noções de perspectivismo e de convergência invadem o campo da interdisciplinaridade que demanda por uma porção de dialogicidade entre áreas de conhecimento. A pressuposição mais elementar da interdisciplinaridade é a combinação de áreas que tendem a se convergir e se complementar, indicando um movimento centrípeto capaz de aproximar as áreas para um eixo de rotação que dá o tom da interdisciplinaridade. No contexto da Educação Intercultural da UFG, a interdisciplinaridade é evocada, mesmo quando não é enunciada, em instantes de abertura dos temas contextuais. O docente quando entra em sala de aula e apresenta um plano de ensino do tema contextual a ser trabalhado com a equipe discente aproxima-se de uma zona limítrofe que afirma o seu campo de conhecimento e os outros campos enunciados pelos estudantes indígenas. Ao trabalhar com o tema contextual Direitos Indígenas pude identificar claramente o instante da interdisciplinaridade quando, a partir da leitura da Declaração das Nações Unidas sobre os Direitos dos Povos Indígenas, de 2006 (ONU, 2008), a turma de estudantes guajajara avança 
discutindo o direito à "festa da menina-moça" para que a humanidade guajajara seja afirmada. A partir desse momento de interlocução, a interdisciplinaridade se dilui e começa a se fazer notar, ainda que encoberta por uma fumaça disciplinar, a transdisciplinaridade.

A transdisciplinaridade abre caminho para uma pedagogia que está além dos conhecimentos institucionalizados, fazendo sobressair de uma fricção entre conhecimentos, uma prática e um fazer pedagógicos que toma os saberes de maneira horizontalizada e alarga possibilidades epistêmicas. Em concordância com Paulo Freire (2013) quando afirma que a desumanização é resultado de uma ordem injusta, entendo que a transdisciplinaridade denuncia a hegemonia e a injustiça dessa ordem ao tensioná-la e confrontá-la com outras lógicas, racionalidades e saberes. Nesses instantes efervescentes transdisciplinares, fusões indicam processos holistas de unificação, sendo que uma re-humanização do humano pode ser ativada e protagonizada pelo próprio sujeito desumanizado. Em uma abordagem transdisciplinar, o movimento que se inaugura é centrífugo afastando do eixo de rotação os elementos constituidores dos saberes e apontando para outras centralidades. A complexidade das dezenas de culturas em interação em ambientes de saber e aprendizagem favorecidos pelos temas contextuais na Educação Intercultural da UFG somente pode ser apreendida mediante a transdisciplinaridade.

Os temas contextuais revelam toda a potência da interculturalidade e da transdisciplinaridade e, quando estudados mais cuidadosamente, permitem que seja percebida sua dimensão transgressora. A feminista negra norte-americana Bell Hooks (1994) ensina que a educação como prática da liberdade se dá por meio da transgressão. Um padrão de poder mundial instituiu uma realidade educacional no mundo ocidental na qual vigoram a opressão, repressão, desinformação, exclusão e constrangimento à multiplicidade de saberes. E, para um exercício mínimo da liberdade, há que se levantar contra essa ordem injusta, sendo assim, a possibilidade mais concreta é a desobediência e a transgressão a essa ordem. Na Educação Intercultural da UFG, os temas contextuais têm sido fontes potenciais de libertação e emancipação para todas as pessoas envolvidas, sejam elas docentes (não indígenas) ou discentes indígenas.

Merece presença aqui uma rápida discussão sobre os impactos que a Educação Intercultural, orientada pelos eixos da interculturalidade e da transdisciplinaridade e realizada 
por meio dos temas contextuais, têm provocado em segmentos outros, além dos corpos docente e discente do curso. As comunidades indígenas, em decorrência dessa dinâmica troca de saberes, tem desenvolvido processos intensos de valorização das próprias culturas. Uma estudante guajajara desenvolveu uma pesquisa sobre a festa do milho em trabalho de final de curso e toda a ação de pesquisa despertou na comunidade guajajara o desejo de realizar essa festa que não acontecia há quase uma década e que é retomada, rememorada e vivenciada por toda a aldeia que se re-encanta com a beleza e importância da festa do milho do povo guajajara. A universidade é outro segmento que tem se transformado e se repensado criticamente em decorrência da Educação Intercultural, já que tem sido desafiada a rever posturas eurocêntricas, desconstruir vieses epistemológicos, denunciar injustiças étnicoraciais historicamente perpetradas e adotar ações reparadoras de processos de exclusão, de opressão e de violação de direitos humanos. A UFG foi a primeira instituição de ensino superior do país a adotar cotas étnico-raciais em todos os seus programas de pós-graduação stricto sensu no ano de 2015, como resposta à demanda de indígenas, além de quilombolas e pessoas negras graduadas e de seguir se qualificando.

Finalmente, a consideração mais robusta a ser apresentada aqui é a de que quando mudanças acontecem em instâncias micro que estruturam edifícios societários, toda a sociedade é levada a se movimentar. Para que se entenda mais aprofundadamente o que está sendo afirmado neste parágrafo final, recordo e corroboro o pensamento da filósofa e feminista negra norte-americana Angela Davis quando demonstra que as mulheres negras ocupam a base da sociedade que é estruturada de forma piramidal, sendo que os homens brancos ocupam seu topo por concentrarem poderes econômicos e laborais e privilégios de raça, gênero e classe. A consideração que Angela Davis apresenta é a de que quando a mulher negra se movimenta, toda a estrutura da sociedade se movimenta (ALVES, 2017) com ela, porque a mulher negra é o sujeito que ocupa a base de sustentação societária. Nesta mesma esteira compreensiva, as dinâmicas movimentações provocadas nas epistemologias e práticas pedagógicas na base micro da Educação Intercultural tem levado toda a sociedade a se movimentar com ela.

\section{Considerações finais}


A interculturalidade é um acontecimento, resultante de um encontro de uma pluralidade e diversidade de culturas, com potencial desestabilizador de padrões de colonialidade e de um poder mundial que instituíram perversos ordenamentos. $\mathrm{Na}$ Educação Intercultural da UFG a interculturalidade, enquanto prática pedagógica decolonial, pode ser apreendida, para efeitos compreensivos e explicativos, por meio dos temas contextuais. A perspectiva intercultural permite acionar bases epistêmicas vinculadas a múltiplos e complexos saberes, colocando-as em interação, integração e ampliação. As discussões aqui desenvolvidas acerca da multi/inter/trans-disciplinaridade indicam a concreta possibilidade de acesso, combinação, alargamento e geração de saberes interculturais.

Os temas contextuais apresentam-se, no âmbito da Educação Intercultural, como alternativas às limitações e enquadramentos disciplinares que foram herdados da ciência moderna e do racionalismo e que seguiam sendo reproduzidos sem questionamentos. Há um inegável tom revolucionário nos temas contextuais que são capazes de problematizar e transformar rígidas estruturas ancoradas em bases colonizadoras. A realização dos temas contextuais tem evidenciado possibilidades de giros epistêmicos decoloniais que, ao mesmo tempo em que denunciam um padrão de poder mundial responsável pela hierarquização e opressão de grupos, indivíduos e saberes, permite que seja estabelecida uma robusta crítica ao moderno modelo europeu-ocidental de racionalidade e, ainda, faz com que a interculturalidade politize um fazer pedagógico.

Quanto às possibilidades no campo dos saberes, os temas contextuais têm demonstrado que uma ampliação de horizontes epistêmicos acontece nos instantes interculturais, ou seja, instantes de instauração de ambientes complexamente dialógicos e reflexivos compostos por agentes que partem de bases culturais diferenciadas e demonstram abertura para perspectivas diferentes das suas. Quanto ao efeito nas pessoas envolvidas em todo o processo pedagógico, na Educação Intercultural da UFG, os temas contextuais têm sido fontes potenciais de libertação e emancipação para todas as pessoas envolvidas, sejam elas docentes (não indígenas) ou discentes indígenas. Como desdobramento das experiências pedagógicas interculturais por meio dos temas contextuais em perspectiva transdisciplinar, uma observação merecedora de destaque são as transformações impactantes tanto nas 
comunidades indígenas, quanto na universidade que tem sido desafiada a rever posturas, desconstruir vieses, denunciar injustiças e adotar ações reparadoras.

\section{Referências}

ALVES, Alê. Angela Davis: "Quando a mulher negra se movimenta, toda a estrutura da sociedade se movimenta com ela”. El País. 27 jul. 2017. Disponível em: $<$ https://brasil.elpais.com/brasil/2017/07/27/politica/1501114503_610956.html $>\quad$ Acesso em: 14 set. 2017.

CARDOSO DE OLIVEIRA, Roberto. Antropologia e a crise dos modelos explicativos. Estudos Avançados, São Paulo, Vol. 9, № 25, p. 213-228, Set./Dez. 1995.

DIAS, Luciana de Oliveira. Desigualdades Étnico-raciais e Políticas Públicas no Brasil. Revista da ABPN, Vol. 3, nº 7, p. 07-28, Mar./Jun. 2012.

FREIRE, Paulo. Pedagogia do Oprimido. Rio de Janeiro: Paz e Terra, 2013. [Primeira edição 1968]

HOOKS, Bell. Teaching to transgress: Education as the practice of freedom. Nova York/Londres: Routledge, 1994.

LUCIANO, Gersem José dos Santos. O Índio Brasileiro: o que você precisa saber sobre os povos indígenas no Brasil de hoje. Brasília: SECADI, LACED/Museu Nacional, 2006.

MIGNOLO, Walter D. Desobediencia epistémica: retórica de la modernidad, lógica de la colonialidad y gramática de la descolonialidad. Buenos Aires: Ediciones del signo, 2010.

NASCIMENTO, André Marques do. Apontamentos críticos sobre concepções de linguagem na formação superior de docentes indígenas: diálogo intercultural como diálogo interepistêmico. Muitas Vozes, Ponta Grossa, v.3, n.1, p. 103-123, 2014.

ONU - Organização das Nações Unidas. Declaração das Nações Unidas sobre os Direitos dos Povos Indígenas. Rio de Janeiro: UNIC, 2008.

PIMENTEL DA SILVA, Maria do Socorro. A Pedagogia da Retomada: decolonização de saberes. Articul. constr. saber., Goiânia, v.2, n.1, p. 204-216, 2017. 
POMBO, Olga. Epistemologia da Interdisciplinaridade. In: Seminário Internacional Interdisciplinaridade, Humanismo, Universidade. Porto, Anais... Universidade do Porto, 2003.

QUIJANO, Aníbal. Colonialidade do poder, eurocentrismo e América Latina. In: LANDER, Edgardo (org). A Colonialidade do Saber: eurocentrismo e ciências sociais - perspectivas latino-americanas. Ciudad Autónoma de Buenos Aires - Argentina: CLACSO, 2005.

WALSH, Catherine E. Decolonial pedagogies walking and asking. Notes to Paulo Freire from AbyaYala. International Journal of Lifelong Education. Volume 34, Issue 1, Special Issue: Education and other modes of thinking in Latin America, p.09-21, 2015.

WALSH, Catherine E. Interculturalidade Crítica e Pedagogia Decolonial: in-surgir, re-existir e re-viver. In: CANDAU, Vera Maria. (Org.). Educação Intercultural na América Latina: entre concepções, tensões e propostas. Rio de Janeiro: 7 Letras, 2009.

WALSH, Catherine. Interculturalidad y Colonialidad del Poder: un pensamiento y posicionamiento “otro" desde la diferencia colonial. In: CASTRO-GÓMEZ, Santiago; GROSFOGUEL, Ramón. El giro decolonial: reflexiones para una diversidad epistémica más allá del capitalismo global. Bogotá: Siglo del Hombre Editores; Universidad Central, Instituto de Estudios Sociales Contemporáneos y Pontificia Universidad Javeriana, Instituto Pensar, 2007. 